\title{
IMPLEMENTASI METODE PEMBELAJARAN PROBLEM BASED LEARNING (PBL) PADA MATA KULIAH PROFESI KEPENDIDIKAN PROGRAM STUDI PIAUD IAIN SURAKARTA
}

\author{
Wiwin Astuti \\ FIT IAIN Surakarta, Jl. Pandawa Pucangan Kartasura Sukoharjo Jawa Tengah Indonesia \\ e-mail: wiwinastuti154@gmail.com
}

\begin{abstract}
The purpose of this study was to determine the effectiveness of the method of learning Problem Based Learning (PBL) in professional education courses in the PIAUD Study Program. This research is experimental. The research population is the secondsemester students of the Early Childhood Islamic Education Study Program (PIAUD) at IAIN Surakarta. Sampling is done by a simple random sampling technique. The sample of this research is class $2 A$ students as an experimental class with 26 students, subjected to problem- based learning and class $2 B$ as a control class with 25 students, subjected to conventional learning methods. The instrument used to collect data was the results of academic achievement tests in the teaching profession. The test instrument was tested before collecting data. Test instruments include validity, different strengths, difficulty levels, and reliability tests. The balance test uses the ttest. The prerequisite tests include the normality test using the Lilliefors method and the homogeneity test using the Bartlet method. Data were analyzed using independent t-tests. Based on the results of the study it was concluded that student achievement that is subjected to PBL learning methods is better than student achievement that is subjected to conventional methods. This shows that the PBL learning method is effective in increasing student achievement in professional education courses in the PIAUD Study Program.
\end{abstract}

Keywords: problem-based learning, conventional, student achievement

\begin{abstract}
ABSTRAK
Penelitian ini bertujuan untuk mengetahui efektivitas metode pembelajaran Problem Based Learning (PBL) pada mata kuliah profesi kependidikan Program Studi PIAUD. Penelitian ini merupakan penelitian eksperimen. Populasi penelitian adalah mahasiswa semester II Program Studi Pendidikan Islam Anak Usia Dini (PIAUD) di IAIN Surakarta. Pengambilan sampel dilakukan dengan teknik simple random sampling. Sampel penelitian ini adalah mahasiswa kelas $2 A$ sebagai kelas eksperimen dengan jumlah siswa 26, dikenai metode pembelajaran problem-based learning dan mahasiswa kelas $2 B$ sebagai kelas kontrol dengan jumlah siswa 25 , dikenai metode pembelajaran konvensional. Instrumen yang digunakan untuk mengumpulkan data adalah hasil tes prestasi belajar mata kuliah profesi kependidikan. Instrumen tes telah diuji sebelum mengumpulkan data. Instrumen uji meliputi uji validitas, kekuatan berbeda, tingkat kesulitan dan uji reliabilitas. Uji keseimbangan menggunakan uji-t. Uji prasyarat meliputi uji normalitas menggunakan metode Lilliefors dan uji homogenitas menggunakan metode Barttlet. Data dianalisis dengan menggunakan independent $t$ test. Berdasarkan hasil penelitian diperoleh kesimpulan bahwa prestasi belajar
\end{abstract}


mahasiswa yang dikenai metode pembelajaran PBL lebih baik dari prestasi mahasiswa yang dikenai metode konvensional. Hal tersebut menunjukkan bahwa metode pembelajaran PBL efektif meningkatkan prestasi belajar mahasiswa pada mata kuliah profesi kependidikan Program Studi PIAUD.

Kata Kunci: problem based learning, konvensional, prestasi belajar

\section{PENDAHULUAN}

Mahasiswa Pendidikan Islam Anak Usia Dini (PIAUD) merupakan calon guru yang disiapkan untuk mendidikan jenjang Pendidikan Anak Usia Dini (PAUD). Mahasiswa sebagai calon guru dituntut untuk memiliki pengetahuan mengenaio profesionalisme guru. Profesionalisme merupakan derajat penampilan atau performance seseorang dalam melaksanakan pekerjaan atau profesinnya dengan tiga prinsip, yakni well educated, well trained, well trained, dan well paid (Suparmin, 2015). Berdasarkan prinsip tersebut maka seorang pendidik harus memperoleh pendidikan yang tinggi, mendapat pelatihan yang memadahi, dan menerima gaji yang sesuai profesionalisme. Oleh karena itu Institut Agama Islam Negeri (IAIN) Surakarta membekali calon guru PAUD untuk mendalami mata kuliah profesi kependidikan.

Mata kuliah profesi kependidikan diberikan kepada mahasiswa dengan tujuan agar mahasiswa sebagai calon guru memiliki bekal pengetahuan mengenai profesi kependidikan dalam Pendidikan Islam Anak Usia Dini sebagai dasar menjadi calon guru professional. Guru adalah pendidik profesional dengan tugas utama mendidik, mengajar, membimbing, mengarahkan, melatih, menilai, dan mengevaluasi peserta didik pada pendidikan anak usia dini jalur pendidikan formal, pendidikan dasar, dan pendidikan menengah (Undang-Undang tentang Guru dan Dosen Nomor 14 Tahun 2005, n.d.). Guru sebagai pendidik professional harus mempunyai 4 kompetensi, yaitu kompetensi pedagogik, kompetensi kepribadian, kompetensi sosial, dan kompetensi professional (Yahya, 2013). Oleh sebab itu, dosen sebagai pengajar di perguruan tinggi harus mampu membentuk mahasiswa calon guru agar mampu menguasai keempat kompetensi tersebut.

Berdasarkan identifikasi isu yang dilakukan program Studi PIAUD IAIN Surakarta, pengetahuan mahasiswa mengenai profesi kependidikan masih rendah. Proses belajar mengajar di universitas masih banyak menggunakan metode konvensional, yaitu ceramah. Adapun beberapa dosen sudah menerapkan motode pembelajaran kooperatif. Namun, dalam pelaksanaannya masih belum optimal. Hal tersebut membuat mahasiswa kurang antusias dalam proses permbelajaran di kelas. Oleh karena itu, peranan seorang dosen dituntut untuk dapat mengubah dan mencairkan suasana belajar yang menyenangkan dengan menerapkan metode pembelajaran yang inovatif dan menyenangkan. Salah satu cara yang dapat dilakukan untuk meningkatkan kualitas pembelajaran 
pada mata kuliah profesi kependidikan adalah dengan mengimplementasikan metode pembelajaran yang aktif dan menyenangkan, yaitu Problem Based Learning (PBL).

Problem Based Learning (PBL) atau Pembelajaran Berbasis Masalah merupakan inovasi dalam pembelajaran, karena melalui metode $P B L$ kemampuan berpikir mahasiswa betul-betul dioptimalisasikan. Mahasiswa dapat mengembangkan kemampuan berpikirnya secara berkesinambungan melalui proses kerja kelompok yang sistematis (Hamzah, 2014). Panen (Rusmono, 2014) mengatakan bahwa dalam model $P B L$, mahasiswa diharapkan terlibat dalam proses penelitian yang mengharuskannya untuk mengidentifikasi pemasalahan, mengumpulkan data, dan menggunakan data tersebut untuk pemecahan masalah. Smith dan Ragan (Rusmono, 2014) menjelaskan lebih lanjut bahwa model $P B L$ merupakan usaha membentuk suatu proses pemahaman isi suatu materi pembelajaran pada seluruh kurikulum.

Tujuan utama $P B L$ bukanlah penyampaian sejumlah besar pengetahuan kepada mahasiswa, melainkan pada pengembangan kemampuan berfikir kritis dan kemampuan pemecahan masalah sekaligus megembangkan kemampuan mahasiswa untuk secara aktif membangun pengetahuan sendiri (Kurniasih, 2014). PBL juga dimaksudkan untuk mengembangkan kemandirian belajar dan keterampilan sosial. Kemandirian belajar dan keterampilan sosial itu dapat terbentuk ketika mahasiswa berkolaborasi untuk mengidentifikasi informasi, strategi, dan sumber belajar yang relevan untuk menyelesaikan masalah. Adapun langkah-langkah dalam pembelajaran model pembelajaran Problem Based Learning (PBL) adalah sebagai berikut: (Fase 1) Mengorientasikan mahasiswa kepada masalah, (Fase 2) Mengorganisasikan mahasiswa untuk belajar, (Fase 3) Membatu penyelidikan mandiri dan kelompok, (Fase 4) Mengembangkan dan menyajikan hasil karya serta memamerkannya, dan (Fase 5) Menganalisis dan mengevaluasi proses pemecahan masalah (Amir, 2010).

Salah satu tujuan Program Studi PIAUD Fakultas Ilmu Tarbiyah (FIT) adalah menghasilkan lulusan yang berkarakter islami, berdaya saing internasional di bidang Pendidikan Islam Anak Usia Dini sesuai dengan perkembangan IPTEK (Mudofir et al., 2019). IAIN Surakarta sebagai lembaga pendidikan berusaha mewujudkan pelayanan pendidikan yang bermutu bagi masyarakat. Hal tersebut dilakukan demi menghasilkan lulusan yang berkualitas. Demi mewujudkan misi tersebut penulis mengangkat tema optimalisasi metode pembelajaran Problem Based Learning (PBL) pada mata kuliah profesi kependidikan.

\section{METODE}

Bentuk penelitian yang digunakan adalah penelitian kuantitatif berupa eksperimen. Penelitian eksperimen dilakukan dengan cara membandingkan hasil kelompok eksperimen dengan kelompok kontrol untuk mengetahui sebab-akibat (cause and effect relationship) atau pengaruh 
suatu tindakan (Arifin, 2011). Tujuan utama penelitian ini adalah mengetahui efektivitas metode pembelajaran Problem Based Learning (PBL) pada mata kuliah profesi kependidikan. Responden dalam penelitian ini dikelompokkan menjadi 2 kelompok. Kelompok pertama adalah kelas eksperimen, yaitu kelas yang dikenai pembelajaran menggunakan metode $P B L$. Kelompok kedua adalah kelas kontrol. Kelas kontrol dikenai metode pembelajaran konvensional yaitu ceramah.

Desain penelitian ini dilakukan dengan membandingkan prestasi belajar mahasiswa uji coba pada kelompok eksperimen dan kelompok kontrol. Populasi penelitian adalah mahasiswa semester II program studi Pendidikan Islam Anak Usia Dini (PIAUD) di IAIN Surakarta.

Sampel penelitian ini adalah mahasiswa kelas 2A sebagai kelas eksperimen dengan jumlah siswa 26, dikenai metode pembelajaran problem-based learning dan mahasiswa kelas 2B sebagai kelas kontrol dengan jumlah siswa 25, dikenai metode pembelajaran konvensional. Sebelum dilakukan eksperimentasi dilakukan uji keseimbangan, uji normalitas dan homogenitas pada sampel tersebut dan diperoleh bahwa kelas eksperimen dan kelas kontrol seimbang, berdistribusi normal dan sampel berasal dari populasi homogen. Teknik pengumpulan data yang dilakukan peneliti berupa tes dan dokumentasi. Peneliti menggunakan teknik tes untuk mengukur prestasi belajar mahasiswa dalam pembelajaran setelah dilakukan tindakan. Bentuk tes yang digunakan adalah soal pilihan ganda, dimana mahasiswa dapat memilih jawaban yang telah disediakan.

Pengambilan sampel dilakukan dengan teknik simple random sampling. Instrumen yang digunakan untuk mengumpulkan data adalah tes prestasi belajar. Sebelum digunakan untuk pengumpulan data, instrumen tes telah diuji cobakan terlebih dahulu. Penilaian validitas isi dilakukan oleh validator. Uji coba instrument meliputi uji validitas, daya beda, tingkat kesukaran dan reliabilitas. Uji keseimbangan menggunakan uji-t. Uji prasyarat meliputi uji normalitas menggunakan metode uji Lilliefors dan uji homogenitas menggunakan metode Barttlet. Teknik analisis data menggunakan independent t-test.

\section{HASIL DAN PEMBAHASAN}

Data prestasi belajar mahasiswa diperoleh dengan alat ukur tes yang terdiri dari 25 butir soal. Berdasarkan hasil penelitian deskripsi data prestasi belajar mata kuliah profesi kependidikan pada mahasiswa kelas eksperimen nilai tertinggi 100 dan terendah 52 dengan $n=26$. Sedangkan hasil penelitian deskripsi data prestasi belajar mata kuliah profesi kependidikan pada mahasiswa kelas kontrol nilai tertinggi 92 dan terendah 44 dengan $n=25$.

Pengujian prasyarat analisis meliputi uji normalitas dan uji homogenitas. Hasil perhitungan uji normalitas disajikan diperoleh data sebagai berikut: 


\begin{tabular}{ccccc}
\hline Populasi yang diuji & $\mathbf{N}$ & $\mathbf{L}_{\text {obs }}$ & DK & Kesimpulan \\
\hline Kelas Eksperimen & 26 & 0,11 & $>0,1737$ & Normal \\
Kelas Kontrol & 25 & 0,1204 & $>0,1772$ & Normal \\
\hline
\end{tabular}

Tabel 1. Data Hasil Uji Normalitas

Tabel 1. di atas menunjukkan semua sampel pada masing-masing populasi berdistribusi normal, sehingga dapat disimpulkan bahwa sampel berasal dari populasi yang berdistribusi normal. Hasil perhitungan uji homogenitas dengan taraf signifikasi 5\% menunjukkan bahwa $\chi_{\text {hitung }}^{2}=0,418$ sedangkan $\chi_{\text {tabel }}^{2}=3,841$ sehingga diperoleh $\chi_{\text {hitung }}^{2}<\chi_{\text {tabel }}^{2}$. Hal tersebut menunjukkan bahwa data mempunyai variansi yang sama atau homogen.

Seletah diketahui bahwa data-data yang diuji berdistribusi normal dan homogen maka dapat dilakukan uji hipotesis. Uji hipotesis yang dilakukan dalam penelitian ini menggunakan independent t-test. Berdasarkan hasil perhitungan diperoleh $t_{\text {obs }}=2,177$ sedangkan $\mathrm{DK}=$ $\{t \mid t>1,677\}$. Hal ini menunjukkan bahwa $t_{o b s} \in$ DK sehingga $H_{0}$ ditolak yang berarti efektifitas metode baru lebih baik dari pada metode lama.

Hasil uji Indipendent t-test menunjukkan bahwa metode pembelajaran Problem Based Learning $(P B L)$ pada mata kuliah profesi kependidikan efektif untuk meningkatkan prestasi belajar mahasiswa PIAUD IAIN Surakarta.

Temuan di atas mendukung hasil penelitian Muhson (2009), Wulandari et al. (2011), Amiluddin \& Sugiman (2016), Suparya (2016), dan Arman (2019) yang menemukan bahwa metode $P B L$ berpengaruh positif terhadap prestasi belajar mahasiswa. Hamzah (2014) dalam penelitiannya mengenai Model-Model Pembelajaran pada Program Studi Pendidikan Guru Madrasah Ibtidaiyah (PGMI) STAIN Samarinda juga mengemukakan bahwa PBL menjadi sebuah alternatif berkaitan dengan penggunaan intelegensi dari dalam diri individu yang berada dalam sebuah kelompok orang atau lingkungan untuk memecahkan masalah yang bermakna, relevan dan kontekstual.

Temuan ini juga sejalan dengan pendapat Majid dan Rochman (2014) yang menyatakan bahwa Problem Based Learning (PBL) merupakan sebuah model pembelajaran yang menyajikan masalah kontekstual sehingga merangsang pembelajar untuk belajar. Model pembelajaran berbasis masalah efektif meningkatkan keterampilan berpikir kritis mahasiswa. Mahasiswa memperoleh keterampilan yang berguna dalam pemecahan masalah sehingga mampu meningkatkan prestasi belajarnya. Model $P B L$ seperti ini sebenarnya sangat relevan dengan kondisi modern saat ini. Pendidikan pada abad modern ini bersentuhan dengan problematika dalam dunia nyata, baik secara internal maupun secara eksternal. 
Tahap pertama pada $P B L$ memungkinkan untuk melatih kemampuan berpikir mahasiswa yang berdampak pada meningkatnya hasil belajar mahasiswa. Tahap awalnya $P B L$ yaitu orientasi masalah, dosen menyajikan gambar atau video yang berkaitan dengan problematika kependidikan yang terjadi di Indonesia. Pada tahap ini, mahasiswa bersama kelompoknya melakukan kegiatan perumusan masalah terhadap gambar atau video yang ditampilkan. Tahap kedua $P B L$ yaitu organisasi belajar, mahasiswa melakukan kegiatan merancang percobaan yang meliputi menentukan tujuan dan cara kerja untuk menyelesaikan masalah yang ada. Tahap ketiga $P B L$ yaitu penyelidikan mandiri dan kelompok, mahasiswa melakukan percobaan sesuai rancangan percobaan yang telah dibuat sebelumnya. Tahap keempat $P B L$ yaitu memamerkan hasil karya berupa sosusi penyelesaian terhadap problematika yang terjadi. Sedangkan tahap kelima $P B L$ yaitu evaluasi, mahasiswa melakukan refleksi terhadap proses pemecahan masalah yang telah dilakukan.

\section{KESIMPULAN DAN SARAN}

Kesimpulan yang diperoleh dari uji efektifitas metode pembelajaran melalui eksperimen ini menunjukkan bahwa metode pembelajaran $P B L$ efektif meningkatkan prestasi belajar mahasiswa pada mata kuliah profesi kependidikan Program Studi PIAUD IAIN Surakarta.

Berdasarkan hasil penelitian yang telah dilakukan, hendaknya dosen dapat menggunakan metode pembelajaran Problem Based Learning (PBL) pada mata kuliah profesi kependidikan. Penerapan metode pembelajaran Problem Based Learning $(P B L)$ dalam mata kuliah profesi kependidikan dapat meningkatkan mutu pembelajaran mahasiswa PIAUD khususnya dan mutu pendidikan di perguruan tinggi pada umumnya. Metode pembelajaran Problem Based Learning $(P B L)$ dapat dijadikan sebagai salah satu rujukan dalam pemilihan metode pembelajaran untuk proses perkuliahan sehingga mahasiswa lebih termotivasi saat proses belajar mengajar. Hasil penelitian ini juga dapat dijadikan rujukan terhadap penelitian lain yang relevan pada waktu yang akan datang.

\section{DAFTAR PUSTAKA}

Amiluddin, R., \& Sugiman, S. (2016). Pengaruh Problem Posing dan PBL terhadap Prestasi Belajar, dan Motivasi Belajar Mahasiswa Pendidikan Matematika. Jurnal Riset Pendidikan Matematika, 3(1), 100-108. https://doi.org/10.21831/jrpm.v3i1.7303

Amir, T. (2010). Inovasi Pendidikan Melalui Problem Based Learning: Bagaimana Pendidik Memberdayakan Pemelajar di Era Pengetahuan. Prenada Media Group.

Arifin, Z. (2011). Penelitian Pendidikan (Metode dan Paradikma Baru). PT Remaja Rosdakarya.

Arman, A. M. (2019). The Effectiveness of Problem Based Learning Method on Students' Achievement in An Analog Electronics Course at Palestine Polytechnic University. Transactions on Networks and Communications, 7(6), 27-33. 
https://doi.org/10.14738/tnc.76.7586

Hamzah, S. H. (2014). Model-Model Pembelajaran pada Program Studi Pendidikan Guru Madrasah Ibtidaiyah (PGMI) STAIN Samarinda. FENOMENA, 6(1), 125-137. https://doi.org/10.4324/9781315853178

Kurniasih, I. (2014). Sukses Megimplementasikan Kurikulum 2013. Kata Pena.

Majid, A., \& Rochman, C. (2014). Pendekatan Ilmiah dalam Implementasi Kurikulum 2013. PT Remaja.

Mudofir, Munadi, M., Bakri, S., Salman, A. M. Bin, Hasbana, A., Hudaya, Wiyono, A. S., Khuriyah, Fu'adi, R., Purwanto, Nashiruddin, M., Saputro, E. C., Hafidh, A., Faishol, A., Hartono, P. R. R. H., Rusmayanti, D., \& Musthofa, W. (2019). Panduan Akademik IAIN Surakarta 2019-2020. IAIN Surakarta.

Muhson, A. (2009). Peningkatan Minat Belajar dan Pemahaman Mahasiswa melalui Penerapan Problem-Based Learning. Jurnal Kependidikan, 39(November), 171-182.

Rusmono. (2014). Strategi Pembelajaran dengan Problem Based Learning Itu Perlu. Ghalia Indonesia.

Suparmin. (2015). Profesi Kependidikan. FATABA Press.

Suparya, I. K. (2016). Penerapan Model Problem Base Learning Melalui Lesson Study Untuk Meningkatkan Kemampuan Berpikir Kritis Pada Mahasiswa Jurusan Pendidikan Guru Pendidikan Anak Usia Dini. 1(1), 69-83.

Undang-Undang tentang Guru dan Dosen Nomor 14 Tahun 2005.

Wulandari, N., Sjarkawi, \& M, D. (2011). Pengaruh Problem Based Learning dan Kemampuan Berpikir Kritis terhadap Hasil Belajar Mahasiswa. Tekno-Pedagogi, 1(1), 14-24.

Yahya, M. (2013). Profesi Tenaga Kependidikan (B. A. Saebani (ed.); 1st ed.). CV Pustaka Setia. 